\title{
Foundational Performance Analyses of Pressure Gain Combustion Thermodynamic Benefits for Gas Turbines
}

Daniel E. Paxson

Glenn Research Center, Cleveland, Ohio

Thomas A. Kaemming

Innovative Scientific Solutions, Inc., Dayton, Ohio 


\section{NASA STI Program . . . in Profile}

Since its founding, NASA has been dedicated to the advancement of aeronautics and space science. The NASA Scientific and Technical Information (STI) program plays a key part in helping NASA maintain this important role.

The NASA STI Program operates under the auspices of the Agency Chief Information Officer. It collects, organizes, provides for archiving, and disseminates NASA's STI. The NASA STI program provides access to the NASA Aeronautics and Space Database and its public interface, the NASA Technical Reports Server, thus providing one of the largest collections of aeronautical and space science STI in the world. Results are published in both non-NASA channels and by NASA in the NASA STI Report Series, which includes the following report types:

- TECHNICAL PUBLICATION. Reports of completed research or a major significant phase of research that present the results of NASA programs and include extensive data or theoretical analysis. Includes compilations of significant scientific and technical data and information deemed to be of continuing reference value. NASA counterpart of peer-reviewed formal professional papers but has less stringent limitations on manuscript length and extent of graphic presentations.

- TECHNICAL MEMORANDUM. Scientific and technical findings that are preliminary or of specialized interest, e.g., quick release reports, working papers, and bibliographies that contain minimal annotation. Does not contain extensive analysis.

- CONTRACTOR REPORT. Scientific and technical findings by NASA-sponsored contractors and grantees.
- CONFERENCE PUBLICATION. Collected papers from scientific and technical conferences, symposia, seminars, or other meetings sponsored or cosponsored by NASA.

- SPECIAL PUBLICATION. Scientific, technical, or historical information from NASA programs, projects, and missions, often concerned with subjects having substantial public interest.

- TECHNICAL TRANSLATION. Englishlanguage translations of foreign scientific and technical material pertinent to NASA's mission.

Specialized services also include creating custom thesauri, building customized databases, organizing and publishing research results.

For more information about the NASA STI program, see the following:

- Access the NASA STI program home page at http://www.sti.nasa.gov

- E-mail your question via the Internet to help@ sti.nasa.gov

- Fax your question to the NASA STI Help Desk at $443-757-5803$

- Telephone the NASA STI Help Desk at 443-757-5802

- Write to: NASA Center for AeroSpace Information (CASI) 7115 Standard Drive Hanover, MD 21076-1320 


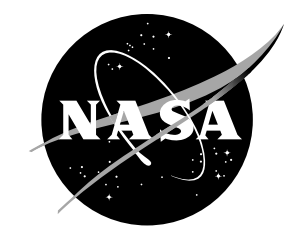

\section{Foundational Performance Analyses of Pressure Gain Combustion Thermodynamic Benefits for Gas Turbines}

Daniel E. Paxson

Glenn Research Center, Cleveland, Ohio

Thomas A. Kaemming

Innovative Scientific Solutions, Inc., Dayton, Ohio

Prepared for the

50th Aerospace Science Conference

sponsored by the American Institute of Aeronautics and Astronautics

Nashville, Tennessee, January 9-12, 2012

National Aeronautics and

Space Administration

Glenn Research Center

Cleveland, Ohio 44135 
This report is a formal draft or working paper, intended to solicit comments and ideas from a technical peer group.

This report contains preliminary findings, subject to revision as analysis proceeds.

Level of Review: This material has been technically reviewed by technical management.

Available from

NASA Center for Aerospace Information 7115 Standard Drive

Hanover, MD 21076-1320
National Technical Information Service 5301 Shawnee Road Alexandria, VA 22312

Available electronically at http://www.sti.nasa.gov 


\title{
Foundational Performance Analyses of Pressure Gain Combustion Thermodynamic Benefits for Gas Turbines
}

\author{
Daniel E. Paxson \\ National Aeronautics and Space Administration \\ Glenn Research Center \\ Cleveland, Ohio 44135 \\ Thomas A. Kaemming \\ Innovative Scientific Solutions, Inc. \\ Dayton, Ohio 45440
}

\begin{abstract}
A methodology is described whereby the work extracted by a turbine exposed to the fundamentally nonuniform flowfield from a representative pressure gain combustor (PGC) may be assessed. The method uses an idealized constant volume cycle, often referred to as an Atkinson or Humphrey cycle, to model the PGC. Output from this model is used as input to a scalable turbine efficiency function (i.e., a map), which in turn allows for the calculation of useful work throughout the cycle. Integration over the entire cycle yields mass-averaged work extraction. The unsteady turbine work extraction is compared to steady work extraction calculations based on various averaging techniques for characterizing the combustor exit pressure and temperature. It is found that averages associated with momentum flux (as opposed to entropy or kinetic energy) provide the best match. This result suggests that momentumbased averaging is the most appropriate figure-of-merit to use as a PGC performance metric. Using the mass-averaged work extraction methodology, it is also found that the design turbine pressure ratio for maximum work extraction is significantly higher than that for a turbine fed by a constant pressure combustor with similar inlet conditions and equivalence ratio. Limited results are presented whereby the constant volume cycle is replaced by output from a detonation-based PGC simulation. The results in terms of averaging techniques and design pressure ratio are similar.
\end{abstract}

\subsection{Introduction}

In the last decade, there has been renewed interest in the potential benefits of integrating pressure gain combustion (PGC) devices into gas turbine engines (Refs. 1 to 8). Conventional gas turbine engines undergo steady, subsonic combustion which, though often described as constant pressure, actually results in a total pressure loss. PGC utilizes any number of physical phenomena, including resonant pulsed combustion, constant volume combustion, or detonation, to affect a rise in cycle averaged, or effective pressure across the combustor, while consuming the same amount of fuel as the constant pressure combustor. In most implementations, the rise is achieved with few or no moving parts and without the need for positive displacement components (e.g., pistons). As applied to the gas turbine engine, PGC yields a theoretical thermodynamic benefit in the form of increased availability for the downstream work extracting turbine.

However, all practical PGC processes are fundamentally unsteady (though periodic). This presents two major challenges to PGC benefits analyses. First, the turbine engine community uses steady-state methods for computing performance. Therefore, most initial benefits assessments for advanced gas turbine components, including the unsteady PGC cycles, are done on a steady-state basis. Thus, some sort of averaging procedure is needed to transform the time varying PGC exhaust flow into a single state that adequately represents its availability (i.e., an equivalent total pressure and temperature). There are many ways to average a nonuniform flowfield, and each results in a different state. The first challenge then is to determine which method yields a state which, when used as input to a turbine performance map comes closest to predicting the actual work extraction.

The second challenge, closely related to the first, is to reasonably estimate 'actual work extraction'. Most turbines are designed for steady flows and their performance is described on this basis. A methodology is therefore needed to determine the work extracted in the face of continually varying inlet conditions.

This paper preliminarily addresses these two challenges using a fundamental approach. The PGC device is modeled using an idealized lumped volume (a.k.a., thermodynamic cycle) representation, and a calorically perfect gas assumption (Refs. 9 and 10). Notionally, this may be envisioned as modeling just one combustor 'can' among the many which would comprise the complete combustor, with all undergoing the same cyclic process. As will be shown, the lumped volume approach is convenient as it can be implemented algebraically, using purely thermodynamic relationships. This in turn provides rapid solutions for numerous parametric variations (e.g., combustor inlet conditions, equivalence ratios, turbine exit conditions, etc.).

The output of this model is used as input to a scalable turbine efficiency map. The turbine is assumed to operate in a quasi-steady fashion (i.e., aerodynamic response time is much less than the combustor cycle period). Each infinitesimal unit of mass leaving the combustor (at a different state) is passed through the map, providing an efficiency which, together with 
the combustor state and the imposed turbine exit pressure allows the computation of an infinitesimal work increment. Turbine exit pressure is assumed to be steady, consistent with the model assumption that there are multiple combustor 'cans.' Integrating these increments over all the mass leaving the combustor provides the cycle mass-averaged work extracted.

Output from the combustor is also averaged using different methodologies (Refs. 11 to 13). The available total pressures and temperatures resulting from the different averaging methodologies are used in a standard, steady cycle analysis. Using the same scalable turbine efficiency map, the work extraction based on the averaging methods is calculated. This work is compared to the cycle mass-averaged work over a broad range of operating parameters to statistically determine the accuracy, and therefore utility, of each averaging method as a meaningful figure-of-merit with which to assess PGC performance.

Details of the model, the turbine map, the averaging methods, and the statistical study are presented. Limited results are also presented in which the lumped volume PGC model output is replaced by output from a computational fluid dynamic simulation of a detonative PGC device operating at the design point. The intention is examine whether the PGC mode (e.g., constant volume or detonation) influences the findings.

\subsection{Methodology}

\subsection{PGC Model Description}

An idealized lumped volume (i.e., thermodynamic cycle) blowdown model is used to describe the simplified PGC process. The process may be imagined as follows. A vessel is initially filled with a known quiescent, combustible mixture, at the compressor exit total conditions (station 3). The mixture undergoes an instantaneous constant volume reaction to a post-combustion state. The resulting high pressure fluid is then expanded isentropically to a specified exit pressure through an ideal combustor exit/turbine entrance nozzle. When the pressure in the vessel reaches the initial pressure, the fill process begins. The throat of the exhaust nozzle is sized such that filling occurs very slowly (i.e., infinitesimally small fill Mach number). As such, filling occurs at the initial pressure, and the hot gases still in the tube continue to exit ideally through the exhaust nozzle. The vessel experiences no further expansion during the fill stage. There is no spatial variation.

The calorically perfect gas version of this process is mathematically described as follows. Beginning with the quiescent state, a nondimensional heat addition parameter may be defined.

$$
q_{0}^{\prime} \equiv \frac{\Delta h_{v}}{\gamma R_{g} T_{t 3}(1+a / f)}
$$

Here, and throughout the paper nondimensionalized quantities are denoted with the ' superscript. Unless otherwise specified, they are nondimensionalized by the station 3 total conditions.

The post-combustion state is obtained through a constant volume heat addition process which takes the form:

$$
\begin{gathered}
T_{C V}^{\prime} \equiv \frac{T_{C V}}{T_{t 3}}=1+\gamma(\gamma-1) q_{0}^{\prime} ; \\
P_{C V}^{\prime} \equiv \frac{P_{C V}}{P_{t 3}}=T_{C V}^{\prime} ; \\
\rho_{C V}^{\prime} \equiv \frac{\rho_{C V}}{\rho_{t 3}}=1
\end{gathered}
$$

Due to the assumption that the flow is isentropic after combustion, the entire blowdown and refill process may be described by a single nondimensional governing equation.

$$
\frac{d \rho_{t 4}^{\prime}}{d t^{\prime}}=-\rho_{\text {exit }}^{\prime} u_{\text {exit }}^{\prime} A_{\text {exit }}^{\prime}
$$

Here $u^{\prime} \equiv u / a_{t 3}, A^{\prime} \equiv A / A_{\text {ref }}, t^{\prime} \equiv t a_{t 3} A_{\text {ref }} / V, a$ is the speed of sound, $V$ is the combustor volume and $A_{\text {ref }}$ is an arbitrary reference area. The other states $P_{t 4}^{\prime}$ and $T_{t 4}^{\prime}$ are found from Equation (2) and standard isentropic relations and the equation of state.

$$
P_{t 4}^{\prime}=P_{C V}^{\prime} \rho_{t 4}^{\prime \gamma} ; \quad T_{t 4}^{\prime}=\frac{P_{t 4}^{\prime}}{\rho_{t 4}^{\prime}}
$$

Furthermore, under the ideal nozzle assumption, all quantities on the right hand side of Equation (3) are also functions of $P_{t 4}^{\prime}, T_{t 4}^{\prime}$, and a specified exit pressure (Ref. 14). As such, Equation (3) could be numerically integrated to obtain the temporal distribution of the combustor total conditions. However, for the purposes of this work, such integration is not necessary. The interest here is not in the variation of properties with time per se, it is in the variation of properties with each infinitesimal unit of mass that leaves the combustor and enters the turbine. Such a unit of mass is simply $d m_{\text {exit }}^{\prime}=\rho_{\text {exit }}^{\prime} u_{\text {exit }}^{\prime} A_{\text {exit }}^{\prime} d \tau$ which, from Equation (3), is $-d \rho_{t 4}^{\prime}$. Thus, the distribution of properties with respect to exiting mass may be obtained by simply dividing the nondimensional mass associated with each cycle into a nearly arbitrary number of segments between the values of 1 and 0 (e.g., 1.0, 0.9, 0.8, etc.) and using Equation (4) to calculate the relevant states.

Such a distribution is shown in Figure 1. The heat addition parameter is $q_{0}^{\prime}=4.3$. This corresponds to a typical hydrocarbon fuel with a heating value of $18,266 \mathrm{Btu} / \mathrm{lb}_{\mathrm{m}}$, and an air/fuel ratio of 43.7. The value of $\gamma$ is 1.33 . The station 3 conditions correspond to a compressor pressure ratio of 10 , operating at sea level static conditions, with an adiabatic 
efficiency of 0.9. The inflection point shown at $m_{\text {exit }}^{\prime} \equiv m_{\text {exit }} / m_{\text {initial }}=0.55$ corresponds to the moment when the combustor has completed the blowdown process and has commenced refilling. It can be calculated as

$$
m_{\text {exit_refill }}^{\prime}=1-P_{C V}^{\prime}{ }^{(-1 / \gamma)}
$$

This distribution contains all the information needed to assess turbine work extraction and to perform the averages to be described.

\subsection{Turbine Efficiency Map and Work Extraction}

Turbine performance is often described using maps (Ref. 15) which describe corrected flow rate and efficiency as functions of pressure ratio and corrected speed. For this study however, only the efficiency is needed. The curves comprising an efficiency map are unique to a given turbine design. However, owing to the physics of work extraction, they all have a similar shape. That is, they all possess a maximum at or near the design pressure ratio and speed, and fall off on either side of the design point. This similarity makes it possible to scale a turbine map such that it can represent (albeit crudely) nearly any class of engine (Ref. 16). An example of such a scaled map is shown in Figure 2. It is the one used in the present study. The figure shows efficiency as a function of scaled pressure ratio for various corrected speeds. Two families of curves are shown. One represents a turbine which is sensitive to operation away from the design point. The other is less sensitive. The range of turbine sensitivity shown is arbitrary and intended only to examine if sensitivity impacts unsteady work extraction.

Examining Figure 1, and considering the shape of the Figure 2 curves, it is clear that maximum work extraction will occur with a turbine designed for a pressure ratio $P R_{t}=P_{t 4} / P_{t 5}$ $=P_{t 4}^{\prime} / P_{t 5}^{\prime}$ somewhere between 10 and 28 (with e.g., $P_{t 5}^{\prime}=$ 1.05). However, there is very little known data on turbine efficiency for pressure ratios significantly above the design point. As such, the region of Figure 2 to the left of the peak value can be traced to the literature (Ref. 15), while the region to the right is somewhat speculative (except that it decreases). Nevertheless, it suffices for the purposes of this study.

The impact of turbine design pressure ratio is illustrated in Figure 3. Here, the 'less sensitive' turbine efficiency of Figure 2 at design corrected speed is replotted. Also shown are efficiencies calculated throughout the Figure 1 example cycle using the present map with different $P R_{t \_d e s i g n}$ values. It is assumed here and throughout the paper that the turbine physical speed is fixed over the course of a given PGC cycle. It can be seen that, although all curves reach peak efficiency somewhere during the cycle, the values of $P R_{t}$ design yielding higher mass-averaged efficiency are preferred.

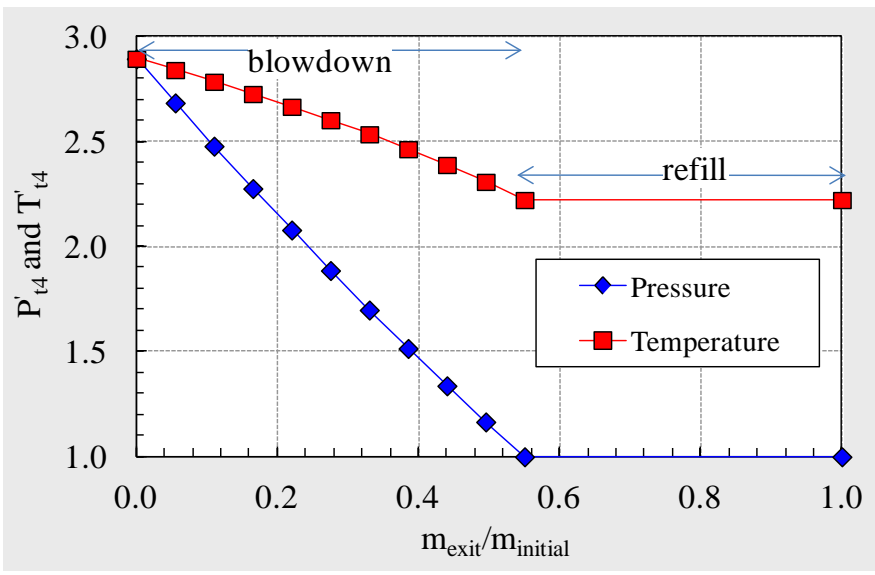

Figure 1.-Model PGC process showing distributions (jump and decay) of pressure and temperature as functions of exiting mass in a combustor segment over the course of one cycle. The upstream compressor pressure ratio is 10 . The equivalence ratio is 0.325 .

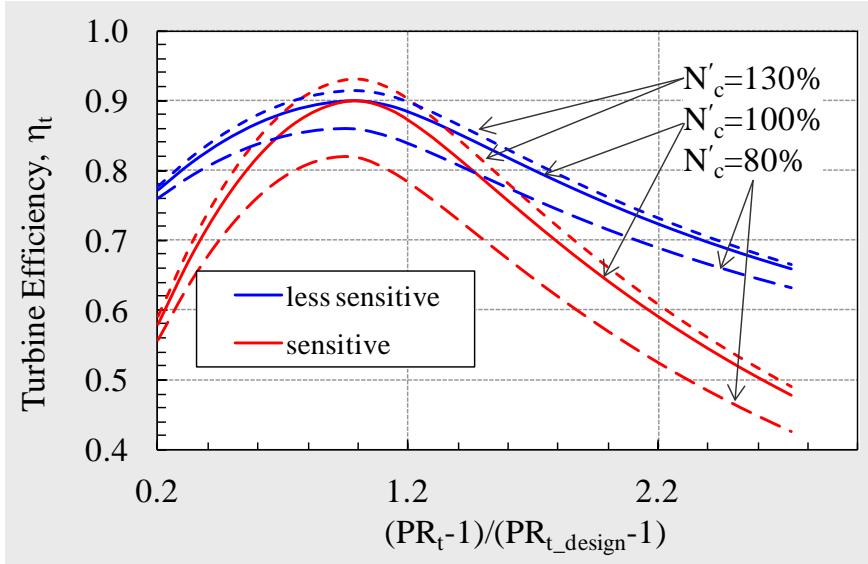

Figure 2.-Scaled turbine efficiency map with notional curves representing a design point sensitive turbine and one that is less sensitive.

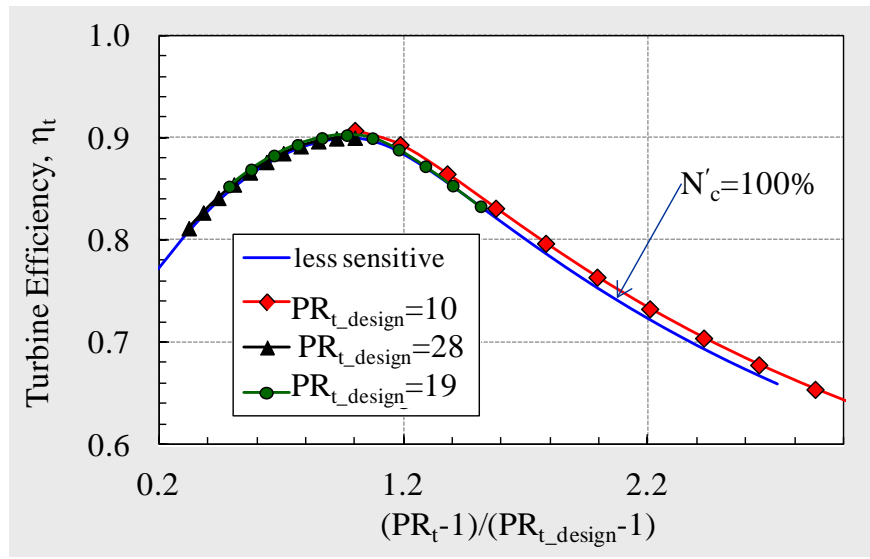

Figure 3.-Trajectory of the Figure 1 example cyclic combustor conditions on the scaled turbine efficiency map for different design pressure ratios. 


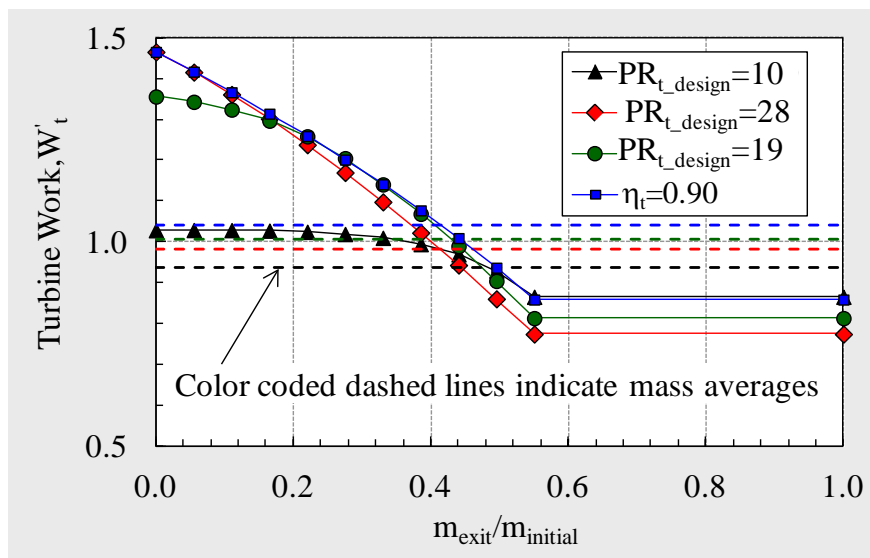

Figure 4.-Distribution of work extraction and cycle massaverages for various values of $\mathrm{PR}_{\mathrm{t}}$ design using the Figure 1 combustor conditions and the scaled turbine map.

In order to calculate cycle mass-averaged work extraction, the turbine map just described is used with the combustor output typified by Figure 1, and an imposed (assumed constant) turbine exit total pressure, $P_{t 5}$, in the following integral ${ }^{*}$.

$$
\begin{aligned}
& \overline{W_{t}^{\prime}} \equiv \frac{(\gamma-1) W_{t}}{m_{\text {initial }} \gamma R_{g} T_{t 3}}=\int_{0}^{1}\left\{\eta_{t} T_{t 4}^{\prime}\left[1-P R_{t}^{-\left(\frac{\gamma-1}{\gamma}\right)}\right]\right\} d m_{\text {exit }}^{\prime} \\
& \eta_{t}=f\left(P R_{t}, T_{t 4}^{\prime}, T_{t 4 \_ \text {design }}^{\prime}, N_{c}, P R_{t_{-} \text {design }}\right)
\end{aligned}
$$

The integrand and integral of Equation (6) are shown in Figure 4 using the Figure 1 data and the same three $P R_{t}$ design values used in Figure 3. Also shown are the integrand and integral using a uniform turbine efficiency equal to the peak value of Figure 2 . The impact of $P R_{t_{-} \text {design }}$ is clearly seen. The maximum mass-averaged work extraction is obtained with a value of $P R_{t \_ \text {design }}=19$.

This example case of turbine optimization illustrates two early conclusions which may be drawn from the current study. First, maximum turbine work extraction for a PGC system requires a turbine designed for a considerably higher pressure ratio than for a conventional constant pressure combustor at similar operating conditions. Second, the work extracted will always be less than if the turbine is assumed to operate at the peak efficiency throughout the cycle.

\footnotetext{
*The imposition of constant $P_{t 5}$ is done in order to close the problem; however, it cannot be formally justified. It is known that nonuniformity is reduced across a single turbine stage (Ref. 1 and 7). Here it is thus assumed that the turbine contains enough stages to provide complete uniformity. Practically, some nonuniformity will undoubtedly remain.
}

\subsection{Averaging Procedures}

The method of evaluating turbine work extraction just described represents the authors' preferred low-order estimate for evaluating the benefits of PGC in the gas turbine environment. Furthermore, it is noted that the process of subjecting a turbine map to the output of a PGC model can be done with any PGC model or simulation. The idealized, lumped volume approach used here is convenient, but not necessary.

However, there remains a desire to assign a single pressure to a PGC device which represents availability; an equivalent pressure which can be used as a figure-of-merit for different PGC designs. Among other applications, such a performance metric could be utilized in existing steady-state based cycle decks in order to evaluate mission benefits. As such, the objective of this and the following section of the paper are to describe various means of evaluating the average exit state which can then be applied to a turbine map and compared, on a work extraction basis, to the preferred method.

\subsubsection{Mass-Averaged Pressure and Temperature $(\bar{P}, \bar{T})$}

This is perhaps the most straightforward averaging technique. For the PGC model used here, the mass-averaged temperature is already known via the conservation of energy.

$$
\overline{T_{t 4}^{\prime}}=1+(\gamma-1) q_{0}^{\prime}
$$

The mass-averaged pressure is found, like all massaverages, as

$$
\overline{P_{t 4}^{\prime}}=\int_{0}^{1} P_{t 4}^{\prime} d m_{\mathrm{exit}}^{\prime}
$$

Unfortunately, while this averaging technique is simple it can be shown that the entropy associated with it is less than the mass-averaged entropy.

$S_{4-\bar{P} \bar{T}}^{\prime}=\ln \left(\frac{\overline{T_{t 4}^{\prime}}\left[\frac{\gamma}{y-1}\right]}{\overline{P_{t 4}^{\prime}}}\right)<\overline{S_{4}^{\prime}}=\int_{0}^{1} \ln \left(\frac{T_{t 4}^{\prime}\left[\frac{\gamma}{y-1}\right]}{P_{t 4}^{\prime}}\right) d m_{\text {exit }}^{\prime}=\ln \left(\frac{T_{C V}^{\prime}\left[\frac{\gamma}{\gamma-1}\right]}{P_{C V}^{\prime}}\right)$ (9)

As such, it would be expected that the average pressure calculated is optimistically high, as is the turbine work extraction calculated by inserting these averages in the steady form of Equation (6).

\subsubsection{Mass-Averaged Entropy and Temperature $(\bar{S}, \bar{T})$}

In this type of averaging the exit state is assigned the massaveraged temperature and entropy shown in Equations (7) and (9), respectively. The associated pressure may be written as follows: 


$$
P_{t 4 \_}^{\prime} \bar{S} \bar{T}=P_{C V}^{\prime}\left(\frac{\overline{T_{t 4}^{\prime}}}{T_{C V}^{\prime}}\right)^{\left[\frac{\gamma}{\gamma-1}\right]}
$$

This type of averaging may be performed and interpreted another way that is conceptually useful. If the combustor exhaust is allowed to expand ideally with the imposed turbine exit pressure interpreted as a static value, then the turbine exit temperature becomes fixed and the following equations hold.

$$
\begin{gathered}
T_{s 5}^{\prime}=\left(P_{s 5}^{\prime} e^{\overline{S_{4}^{\prime}}}\right)^{\frac{\gamma-1}{\gamma}} ; P_{t 4 \_}^{\prime} \bar{s} \bar{T}=P_{s 5}^{\prime}\left(\frac{\overline{T_{t 4}^{\prime}}}{T_{s 5}^{\prime}}\right)^{\frac{\gamma}{\gamma-1}} \\
\frac{\overline{u_{5 i}^{\prime 2}}}{2}=\frac{\left(\overline{T_{t 4}^{\prime}}-T_{s 5}^{\prime}\right)}{(\gamma-1)}
\end{gathered}
$$

Equation 12 represents the ideal mass-averaged kinetic energy that can be developed by the combustor flow. Thus, equivalent total pressure calculated via either Equation (10) or (11) may be interpreted as the total pressure which, when ideally expanded from the mass-averaged total temperature to the turbine exit static pressure, produces the mass-averaged kinetic energy. This is a useful interpretation since it makes somewhat intuitive sense that availability for turbine work extraction might be closely related to availability for developing kinetic energy. On the other hand, the fact that no additional entropy is generated in the averaging process (i.e., there is no penalty in making the flow uniform) suggests that this averaging method too, may prove optimistic.

\subsubsection{Ideal Specific Thrust and Mass-Averaged Temperature $(\bar{C}, \bar{T})$}

Assuming again that each exiting mass unit ideally expands with the imposed turbine exit pressure interpreted as a static value, the ideal specific thrust, or mass-averaged spouting velocity may be calculated as follows.

$$
\overline{u_{5 i}^{\prime}}=\left(\frac{2}{\gamma-1}\right)^{\frac{1}{2}} \int_{0}^{1}\left(T_{t 4}^{\prime}-T_{55}^{\prime}\right)^{\frac{1}{2}} d m_{\mathrm{exit}}^{\prime} \equiv \overline{C_{5}^{\prime}}
$$

Comparing Equations (12) and (13), it is noted that $\overline{u_{5 i}^{\prime 2}} \neq{\overline{u_{5 i}^{\prime}}}^{2}$. The significance of this fundamental inequality is discussed in References 17 and 18. Equation 13 is then used to obtain an equivalent or mixed static pressure.

$$
T_{s 5_{-} \bar{C} \bar{T}}^{\prime}=\overline{T_{t 4}^{\prime}}-\left(\frac{\gamma-1}{2}\right){\overline{u_{5 i}^{\prime}}}^{2}
$$

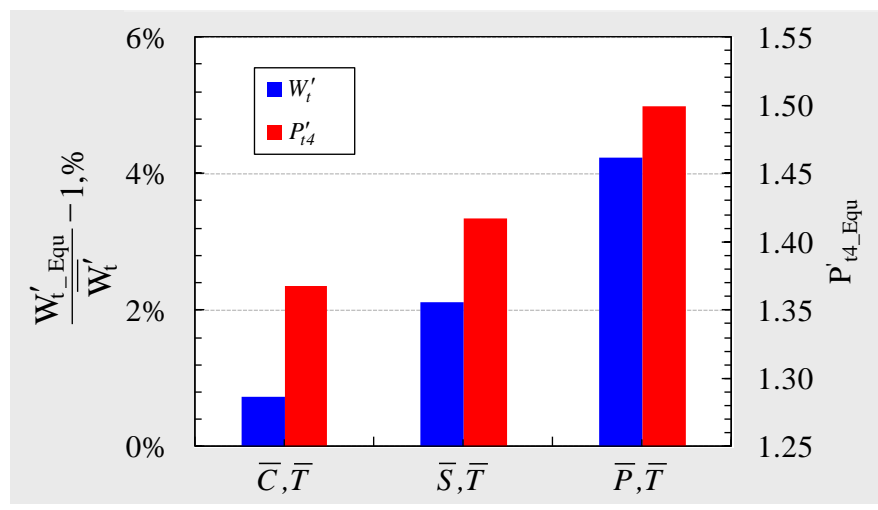

Figure 5.-Equivalent turbine work extraction error and combustor pressure calculated with the various averaging methods described. The Figure 1 combustor conditions were used.

From Equation (14), the equivalent total pressure is then readily obtained as

$$
P_{t 4 \_}^{\prime} \bar{C} \bar{T}=P_{s 5}^{\prime}\left(\frac{\overline{T_{t 4}^{\prime}}}{T_{s 5_{-} \bar{C} \bar{T}}^{\prime}}\right)^{\frac{\gamma}{\gamma-1}}
$$

Using an equation similar to Equation (9), it can be seen that this form of averaging yields a state with greater entropy than the mass-averaged exit value. That is to say, it reflects a loss in availability.

The three averaging methods just described were exercised on the example cycle illustrated in Figure 1. The resulting equivalent total pressures and temperatures were used with the optimized turbine map $\left(P R_{t_{-} \text {design }}=19\right)$ to determine efficiency, and turbine work via the steady form of Equation (6). This equivalent work extraction can be compared to the massaveraged work extraction shown in Figure 4. Figure 5 shows such comparisons along with the equivalent combustor pressures calculated using each of the methods. For this single case study, the spouting velocity or specific thrust averaging method produces the best representation of turbine availability in the sense that the subsequent turbine work calculated most closely matches the mass-averaged turbine work.

\section{$2.4 \quad$ Statistical Study}

In order to capture the possible influences of various operating and design conditions on the averaging methods discussed above, a statistical study was conducted. This study used the same thermodynamic cycle, or lumped volume, analysis methods described above, as well as the same parametric turbine map. The range of design and operating conditions are provided in Table I. The design point was assumed to be at an equivalence ratio of 0.4. All lower equivalence ratios were assumed to be off-design points. 
TABLE I.-RANGE OF CONDITIONS EXAMINED

\begin{tabular}{|c|c|}
\hline Parameter & Valı \\
\hline \multicolumn{2}{|c|}{ 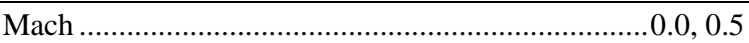 } \\
\hline \multicolumn{2}{|c|}{ 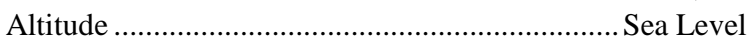 } \\
\hline \multicolumn{2}{|c|}{ CPR } \\
\hline \multicolumn{2}{|c|}{ 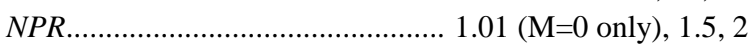 } \\
\hline \multicolumn{2}{|c|}{$\phi_{\text {design }}$} \\
\hline \multicolumn{2}{|c|}{ 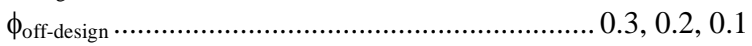 } \\
\hline urbi & \\
\hline
\end{tabular}

Similar to the above analysis, the turbine design point was optimized for each on-design condition to provide the maximum turbine work extraction. A total of 135 points were assessed. Several different averaging techniques were studied besides those presented thus far; however, they are not reported here as they did not provide superior correlation to the turbine work available.

A comparison between the combustor pressure ratio computed using the three averaging techniques and the pressure ratio corresponding to a steady pressure providing the same turbine work at the mass-averaged combustor exit entropy is provided in Figure 6. Similar to the findings of Section 2.3, the specific thrust, or spouting velocity, average provides the best correlation, with an average error of 2 percent. The mass-averaged entropy and temperature provides the next best correlation with an average error 4 percent. The mass-averaged pressure and temperature provides the poorest correlation with an average error of nearly 7 percent. It should also be noted that the latter two methods consistently predict combustor pressure ratios larger than the average pressure ratio for the work available. That is to say, they consistently over-predict availability.

Finally, comparisons of mass-averaged turbine work extraction to equivalent pressure-based steady work extraction using the three averaging techniques are shown in Figure 7. Once again, the specific thrust, or mass-averaged spouting velocity, provides the most accurate correlation for work available. Shown in the figure are the maximum, minimum, average and standard deviation of the error in predicted work available for each of the previously described averaging techniques compared to the actual mass-averaged work computed. Similar to the combustor pressure ratio predictions, the mass-averaged pressure and temperature technique consistently over-predicts the work extraction. Although not shown, it is generally found that the disparities are larger for the sensitive turbine map than for the less sensitive map.

\subsection{Detonative Combustion}

In order to cursorily examine the impact of other PGC modes on the mass-averaged turbine work and averaging approaches presented, a detonative combustor cycle was examined. The combustor inlet conditions, air/fuel ratio, fuel heating value, gas constant, and ratio of specific heats were identical to the Figure 1 example. Simulation was done

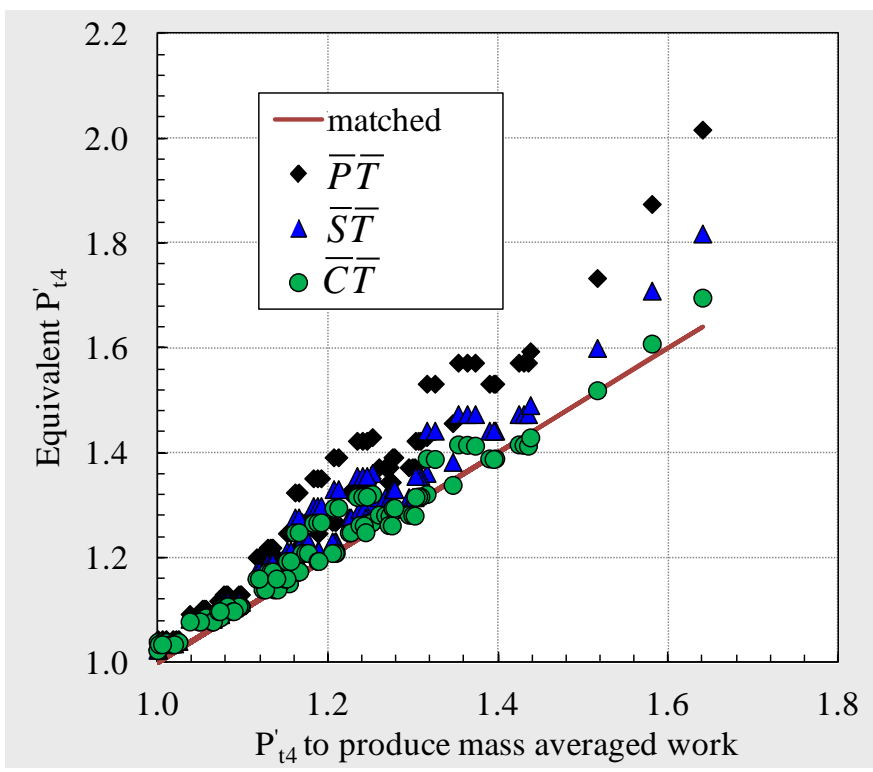

Figure 6.-Combustor pressure ratio corresponding to a steady pressure providing the mass-averaged turbine work versus equivalent combustor pressure ratio using the averaging techniques described.

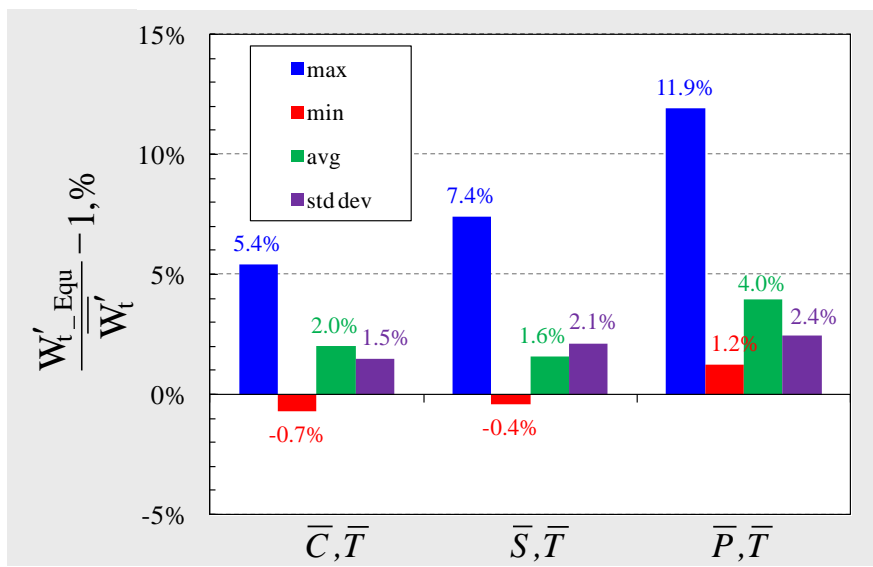

Figure 7.-Turbine work extraction error calculated with the various averaging methods described. The Table 1 engine conditions were used.

using a high resolution, reactive, quasi-one-dimensional, computational fluid dynamics (CFD) code. Details of the code can be found in the literature and will not be presented here in order to maintain focus on the results (Refs. 9 and 12). The simulated combustor section has uniform cross sectional area over 93 percent of its length. The remaining length smoothly transitions to an exit throat with cross sectional area 30 percent that of the uniform cross section region. Combined with an imposed exit static pressure set to 50 percent of the inlet total, choked exit flow is assured throughout the cycle and the average fill Mach number is held to approximately 0.26 .

The complete cycle is conveyed in the plots of Figure 8. which show color contours of nondimensional pressure, 


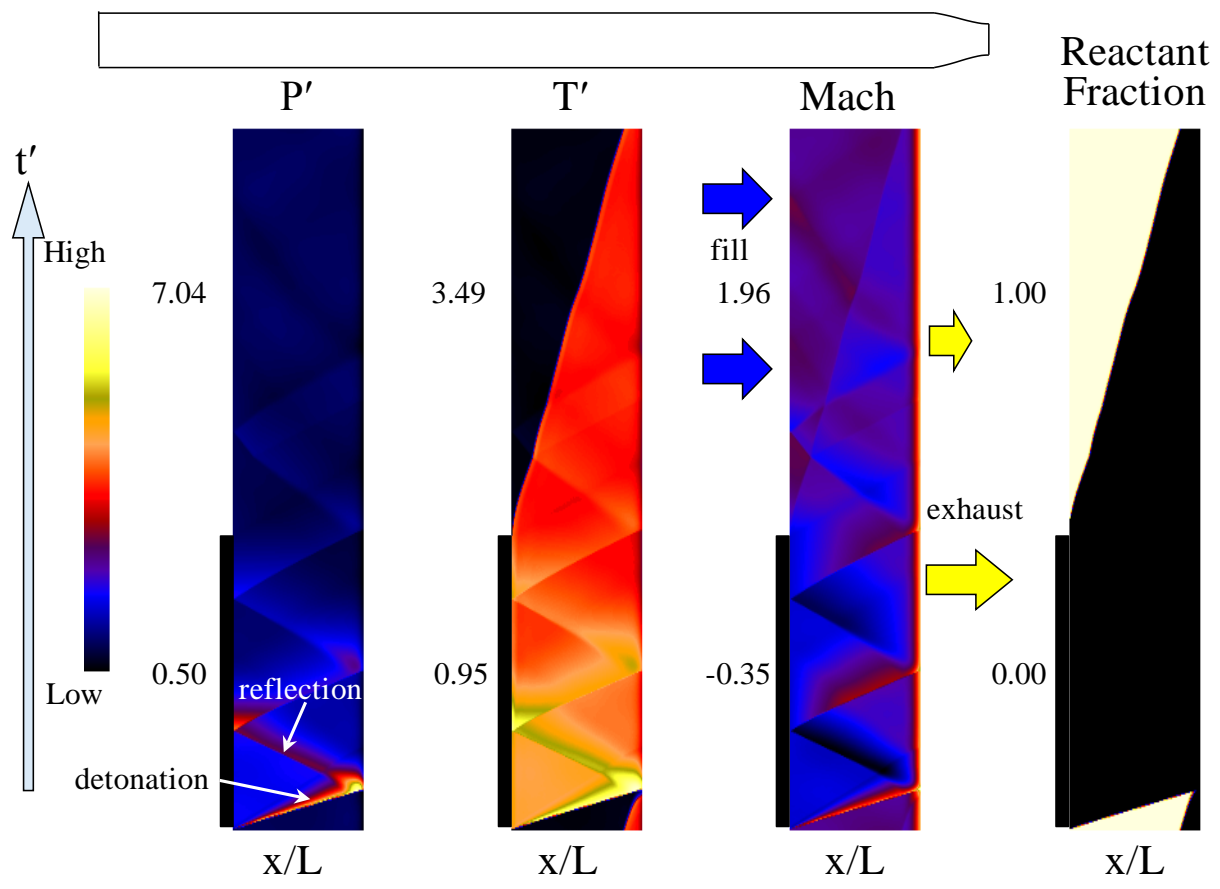

Figure 8.-Contours of pressure, temperature, Mach number and reactant fraction for the sample detonative combustor over the course of one limit cycle.

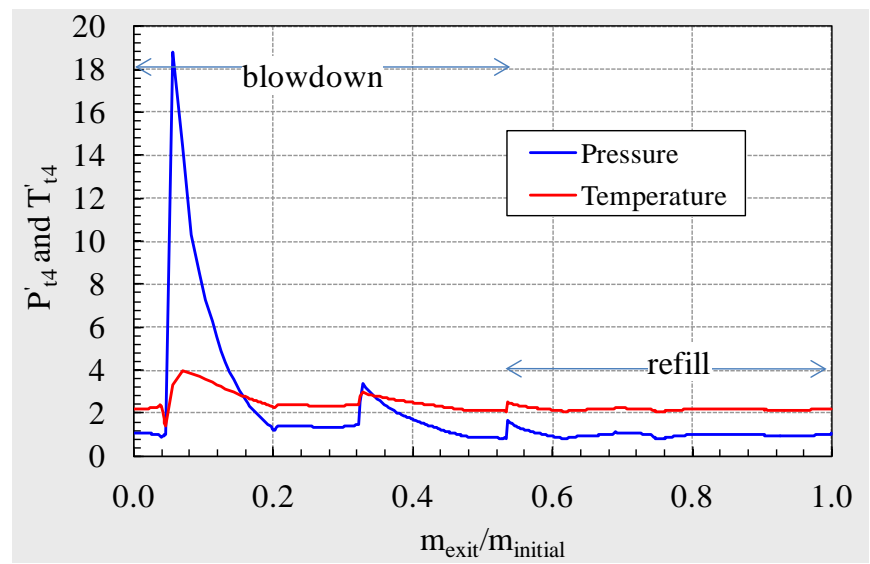

Figure 9.-Detonative PGC process showing distributions of exit plane pressure and temperature as functions of exiting mass in a combustor segment over the course of one cycle. The upstream compressor pressure ratio is 10 . The equivalence ratio is 0.325 .

temperature, Mach number and reactant fraction (mass fraction of detonable mixture) inside the combustor over the course of one limit cycle. Shown next to each contour are the maximum and minimum values of the variable found in the $\mathrm{x}-\mathrm{t}$ space.

The exit flow from this simulation can be integrated to produce a similar detonative distribution to Figure 1 . This is shown in Figure 9. Note that the range of variation is considerably greater in Figure 9 than in Figure 1. This variation has a substantial impact on the work extraction possible with the detonative combustor, as it results in a much broader spanning of the Figure 2 efficiency map. This is shown in Figure 10 which, like Figure 3, displays the efficiency of each mass unit exiting the detonative combustor over the course of the cycle. The design pressure ratio yielding the greatest work extraction from the less sensitive turbine map is $P R_{t_{-} \text {design }}=17$. It can be seen that the variation noted in Figure 9 yields efficiency as low as 0.39 . When this distribution is integrated in Equation (6) it is found that, even though the detonative and constant volume combustion examples have exactly the same chemical energy added, and even though detonative combustion can be shown to produce less entropy than constant volume combustion, the optimized detonation-driven turbine of this example only extracts 92 percent of the work as that of the constant volume-driven turbine.

These results indicate the challenges inherent in coupling a detonative combustor with a turbine in order to realize the combustor's thermodynamic benefits. The broad temperature and pressure swings of the detonative combustion create structural and performance challenges for the turbine. The technical community is actively working the challenges through combined combustor and turbine research efforts (Refs. 19 and 20). Furthermore, the detonative result above is specific to the extreme off-design behavior of the turbine efficiency map used which, as stated earlier, is speculative. Data-based extended turbine maps are needed before any firm conclusions can be drawn. 


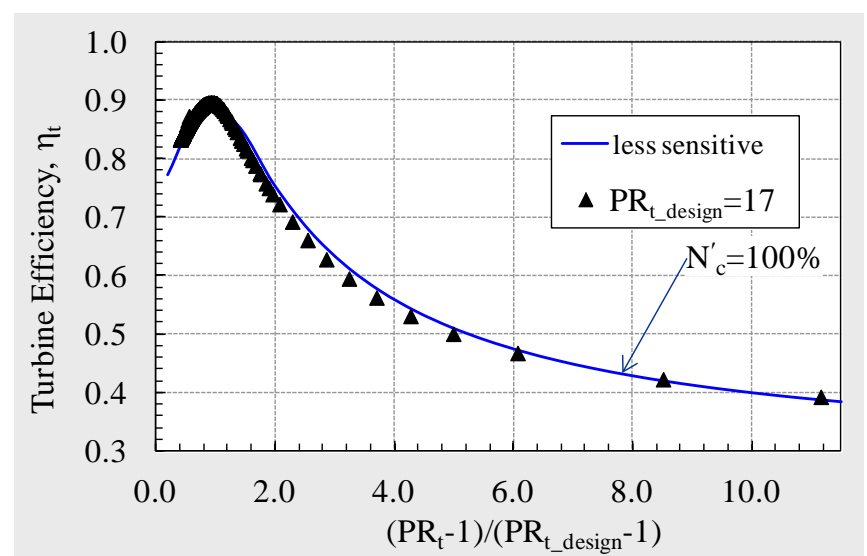

Figure 10.-Turbine efficiency for each mass unit exiting the detonative combustor described by Figure 8.

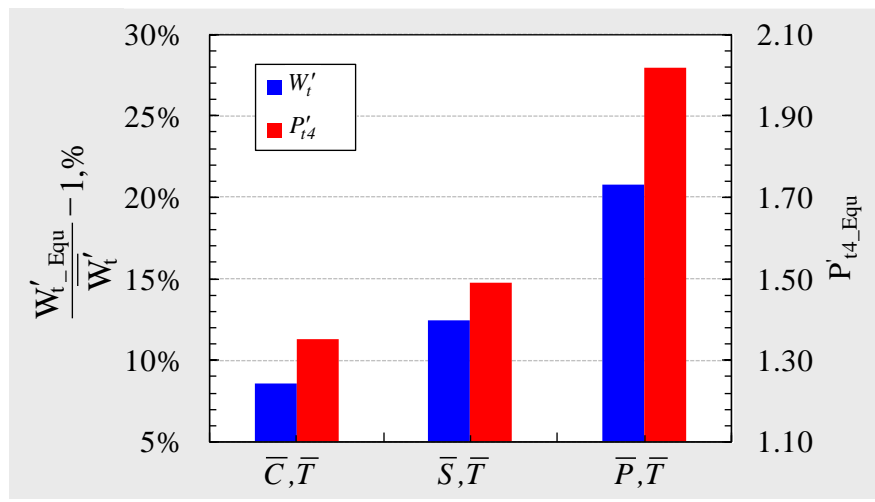

Figure 11.-Equivalent turbine work extraction error and combustor pressure calculated with the various averaging methods described. The Figure 1 combustor conditions were used with the Figure 8 detonative combustor results.

The averaging methods presented can be applied to the detonative combustor example and the equivalent steady work extraction can be compared to the mass-averaged work extraction as was done for Figure 5. This is shown in Figure 11. As with previous results, it is seen that the specific thrust or spouting velocity averaging provides the best match to 'actual' mass-averaged work extraction. However, even this relatively good match shows a much larger error than in any of the constant volume combustor results. Furthermore, and again although it is not shown, the error is even larger for the sensitive turbine map.

\subsection{Discussion}

Referring to Figure 5, Figure 7, and Figure 11, and assuming that the integral of Equation (6) represents the 'actual' mass-averaged turbine work extraction, it is not surprising that the errors between actual work, and work calculated via the stagnation states resulting from the three averaging methods come out as they do. All three methods utilize the mass-averaged total temperature. This is appropriate, as it is a mathematically rigorous measure of the chemical energy added to the working fluid. It is therefore the various averaged pressures that warrant closer examination. Figure 3 and Figure 4, as well as Equation (6), demonstrate that there is a performance penalty (i.e., the turbine is ondesign for only a small fraction of the entire mass processed) associated with nonuniform flows. The best pressure averaging method should produce a loss in availability that is consistent with this penalty.

As mentioned earlier, using the mass-averaged total pressure is straightforward and arguably intuitive. However, as shown in Equation (9), it results in a state which violates the second law of thermodynamics. Averaging procedures may be interpreted as mixing calculations where a nonuniform flow is forced (presumably through dissipative processes such as shearing) to a uniform state. Dissipative forces produce entropy and the mixing calculation should reflect this. Since mass averaging of the total pressure does not, it would be expected to produce the most unrealistically high combustor pressure ratios which in turn produce unrealistically high work extraction estimates. Figure 5, Figure 6, Figure 7, and Figure 11 show this to be precisely the case.

Calculating total pressure by preserving mass-averaged total temperature and entropy (Eqs. (10) to (12)) would also be expected to produce optimistically high combustor pressure ratios. Again, interpreted as a mixing calculation, this method exacts no entropy producing penalty on the nonuniform flow. However, the method does preserve the ideal mass-averaged kinetic energy that a given PGC can produce. For purely thrust producing devices, exhaust kinetic energy is directly proportional to cycle thermal efficiency. It stands to reason then that this thermal efficiency should be related to availability for turbine work extraction. As such, the result that the mass-averaged total temperature and entropy averaging method produces smaller errors than the mass-averaged total temperature and pressure method is expected.

The averaging method preserving mass-averaged temperature and ideal specific thrust or mass-averaged spouting velocity produces the smallest work extraction errors. As noted, this is the only averaging procedure that produces entropy and thus at least cursorily accounts for the work extraction penalty illustrated in Figure 3 and Figure 4. Furthermore, there is a more direct physical rationale for the reduced error. It can be shown that the work extraction from an ideal Pelton-style impulse turbine operating at constant speed is written as follows (Ref. 18).

$$
\overline{W_{t}^{\prime}}=2 U^{\prime}\left(\overline{u_{5 i}^{\prime}}-U^{\prime}\right)
$$

Practical turbines with multiple stages, degrees of reaction, significant axial flow components, and aerodynamic losses have a much more complex work formula; however, the fundamentally proportional relationship between spouting velocity and work extraction remains. Thus, an averaging method based on preserving the ideal spouting velocity is expected to, and does, yield turbine work extraction that closely matches the actual value. 
That being said, it is noted that in the case of the detonative combustor, even the 'best' spouting velocity averaging technique substantially over-predicts availability. The technique produces entropy scaled with the level of flow nonuniformity. Apparently however, it does not produce enough entropy to match the turbine performance penalty illustrated in Figure 10. On the other hand, it is quite possible that this performance penalty arising from an essentially notional efficiency map is unrealistically harsh.

The detonative combustor results bring to light another topic worthy of passing discussion. It is presumed in the dynamic work extraction analysis that the PGC is directly coupled to the turbine. There are PGC concepts in the literature which place a mixing device between the PGC and the turbine ${ }^{21}$. Such devices serve to smooth the flow, though, as with the mixing calculations, at the fluidic cost of producing entropy. Nevertheless, it is entirely possible that for PGC devices with large variations in the flow effluent, the lost availability from mixing (or partial mixing) followed by turbine work extraction from a smoother flowfield could yield more work extraction than direct coupling to a turbine. This is particularly possible if the off-design turbine performance is as sensitive as the example shown. Significant investigations are needed to optimize this trade space.

\subsection{Conclusions}

A methodology was presented for calculating the massaveraged work extracted by a turbine exposed to the fundamentally nonuniform flowfield presented by a pressure gain combustor (PGC). The method is relatively simple, yet provides realistic values for so-called 'actual' work extraction. This actual work extraction was compared to steady work extraction calculations based on turbine inlet states obtained by averaging simulated PGC effluent using several different averaging procedures. The objective was to determine which, if any averaging process provides a representative effective steady state in terms of availability for turbine work extraction. The resulting state, a combustor total exit pressure and temperature, may be used as a convenient performance metric for any PGC system without having to actually dynamically couple it to a turbine.

An averaging procedure was found which preserves massaveraged temperature and ideal specific thrust, or spouting velocity, and provides the best match to the actual work extraction. In a statistical exercise using an idealized constant volume PGC simulation, the work extraction predicted using this averaging technique was well matched to the actual work extraction over a wide range of combustor operating points, with an overall standard deviation of 1.5 percent. When a single operating point comparison was made for a detonative combustor, the specific thrust averaging technique still provided the best match; however, the error in work prediction was approximately 8 percent too high.

Though not a direct objective of the study, it was also found that the design turbine pressure ratio for maximum mass-averaged work extraction is significantly higher (approximately 70 percent) than that for a turbine fed by a constant pressure combustor with similar inlet conditions and equivalence ratio. This finding, while preliminary, has substantial implications when considering the actual design of PGC gas turbines.

In closing, it is reiterated that this study presents a relatively simple, fundamental method to estimate the potential work available from a pressure gain combustor coupled with a turbine. More accurate performance predictions are available from higher fidelity dynamic analyses. Practical combustor and turbine component designs, as well as accurate performance predictions, will require such high fidelity renderings of the true fluid dynamics. 



\section{Appendix-Nomenclature}

A

C

$C P R$

$\Delta h_{v}$

$N_{c}$

$N P R$

$P$

$P R_{t} \quad$ turbine total pressure ratio

$L$

$R_{g}$

$S$

$T$

$U$

V

$W_{t}$

$a$

$a / f$

$m$

$q_{0}$

$t$

$u$

X

$\eta_{t}$

$\phi$ cross sectional area

spouting velocity

compressor pressure ratio, $P_{t 3} / P_{0}$

fuel lower heating value

corrected turbine wheel speed

nozzle pressure ratio, $P_{t 5} / P_{0}$

pressure

combustor length

real gas constant

entropy

temperature

turbine wheel velocity

combustor volume

turbine work

speed of sound

air to fuel ratio (by mass)

mass

mixture heating value

time

velocity

axial distance

turbine efficiency

equivalence ratio, $\frac{(a / f)_{\text {stoichiometric }}}{(a / f)}$ $\gamma$

$\rho$

$\tau$

\section{Subscripts}

CV

Equ

design

exit

i

initial

off-design

ref

$s$

$t$

0

3

4

5

Superscripts

, nondimensional

- $\quad$ mass-averaged

density

equivalent

ideal

reference

static

total

ambient

turbine exit ratio of specific heats

nondimensional time

Constant Volume

at the design point

combustor exit plane

point in combustor cycle when filling with reactant is complete

off of the design point

compressor outlet

turbine inlet (combustor exit) 


\section{References}

1. Caldwell, N., and Gutmark, E., "Performance Analysis of a Hybrid Pulse Detonation Combustor / Gas Turbine System,” AIAA 2008-4880, July 2008.

2. Perkins, H. D., et al., "An Assessment of Pulse Detonation Engine Performance Estimation Methods Based On Experimental Results,” AIAA 2005-3831, July 2005.

3. Paxson, D. E., Perkins, H. D., "Thermal Load Considerations for Detonative Combustion-Based Gas Turbine Engines,” AIAA-2004-3396, July 2004.

4. Rasheed, A., Tangirala, V. E., Vandervort, C. L., Dean, A. J., Haubert, C., "Interactions of a Pulsed Detonation Engine with a 2D Blade Cascade,” AIAA 2004-1207, January 2004.

5. Petters, D. and Felder, J., "Engine System Performance of Pulse Detonation Concepts Using the NPSS Program,” AIAA 2002-3910. July 2002.

6. Smith, C. F., Snyder, P. H., Emmerson, C. W., Nalim, M. R., "Impacts of the Constant Volume Combustor on a Supersonic Turbofan Engine,” AIAA-2002-3916, July 2002.

7. Rouser, K. P., King, P. I., Schauer, F. R., Sondergaard R., Hoke, J. L., "Parametric Study of Unsteady Turbine Performance Driven by a Pulse Detonation Combustor," AIAA 2010-6536, July 2010.

8. Kojima, et al., "Design Study of Turbine for Pulse Detonation Combustor,” AIAA 2007-5081, July 2007.

9. Paxson, D. E., Brophy, C., Bruening, G., "Performance Evaluation of a Pulse Detonation Combustion Based Propulsion System Using Multiple Methods," JANNAF Journal of Propulsion and Energetics, Vol. 3, No. 1, May 2010, pp. 44-55.
10. Kaemming, T., Dyer, R., “The Thermodynamic and Fluid Dynamic Functions of a Pulsed Detonation Engine Nozzle,” AIAA-2004-3916, July 2004.

11. Cumpsty, N. A., Horlock, J. H., “Averaging Nonuniform Flow for a Purpose," Journal of Turbomachinery, V. 128, No. 1, pp. 120-129, January 2006.

12. Paxson, D.E., "Performance Evaluation Method for Ideal Airbreathing Pulse Detonation Engines," Journal of Propulsion and Power, Vol. 20, No. 5, pp. 945-950, 2004.

13. Suresh, A., Hofer, D.C., Tangirala, V.E. "Turbine Efficiency for Unsteady, Periodic Flows,” AIAA 20090504, January 2009.

14. Anderson, J. D., Modern Compressible Flow, McGrawHill, N.Y., 1982, pp. 11-38.

15. Glassman, A. J., ed., Turbine Design and Application, NASA SP-290, 1994.

16. Jones, S.M., "An Introduction to Thermodynamic Performance Analysis of Aircraft Gas Turbine Engine Cycles Using the Numerical Propulsion System Simulation,” NASA/TM-2007-214690, March 2007.

17. Foa, J. V., Elements of Flight Propulsion, Wiley, New York, 1959, pp. 274-283.

18. Paxson, D. E., “A Simplified Model for Detonation Based Pressure-Gain Combustors,” AIAA 2010-6717, July 2010.

19. Kojima, et al., "Design Study of Turbine for Pulse Detonation Combustor,” AIAA 2007-5081, July, 2007.

20. Suresh, A., Hofer, D., Tangirala, V., “Turbine Efficiency for Unsteady Periodic Flows,” AIAA 2009-504, January 2009.

21. Paxson, D. E., Dougherty, K. T., “Ejector Enhanced Pulsejet Based Pressure Gain Combustors: An Old Idea With a New Twist,” AIAA 2005-4216, August 2005. 



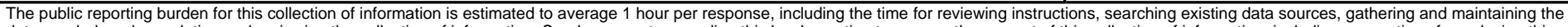

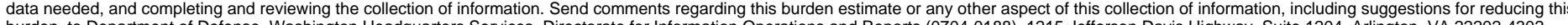

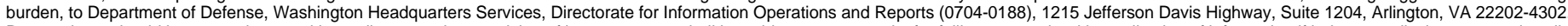

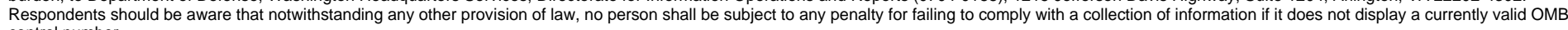

control number.
PLEASE DO NOT RETURN YOUR FORM TO THE ABOVE ADDRESS.

\begin{tabular}{l|l|l}
\hline $\begin{array}{l}\text { 1. REPORT DATE (DD-MM-YYYY) } \\
01-05-2012\end{array}$ & $\begin{array}{l}\text { 2. REPORT TYPE } \\
\text { Technical Memorandum }\end{array}$ & 3. DATES COVERED (FrOm - To)
\end{tabular}

4. TITLE AND SUBTITLE

Foundational Performance Analyses of Pressure Gain Combustion Thermodynamic Benefits

for Gas Turbines

5a. CONTRACT NUMBER

5b. GRANT NUMBER

5c. PROGRAM ELEMENT NUMBER

6. AUTHOR(S)

Paxson, Daniel, E.; Kaemming, Thomas, A.

\section{5d. PROJECT NUMBER}

5e. TASK NUMBER

5f. WORK UNIT NUMBER

WBS 031102.02.03.0832.11

8. PERFORMING ORGANIZATION REPORT NUMBER

E-18174

John H. Glenn Research Center at Lewis Field

Cleveland, Ohio 44135-3191

9. SPONSORING/MONITORING AGENCY NAME(S) AND ADDRESS(ES)

National Aeronautics and Space Administration

Washington, DC 20546-0001

\section{SPONSORING/MONITOR'S ACRONYM(S) \\ NASA}

11. SPONSORING/MONITORING REPORT NUMBER

NASA/TM-2012-217443

\section{DISTRIBUTIONIAVAILABILITY STATEMENT}

Unclassified-Unlimited

Subject Category: 07

Available electronically at http://www.sti.nasa.gov

This publication is available from the NASA Center for AeroSpace Information, 443-757-5802

\section{SUPPLEMENTARY NOTES}

\section{ABSTRACT}

A methodology is described whereby the work extracted by a turbine exposed to the fundamentally nonuniform flowfield from a representative pressure gain combustor (PGC) may be assessed. The method uses an idealized constant volume cycle, often referred to as an Atkinson or Humphrey cycle, to model the PGC. Output from this model is used as input to a scalable turbine efficiency function (i.e., a map), which in turn allows for the calculation of useful work throughout the cycle. Integration over the entire cycle yields mass-averaged work extraction. The unsteady turbine work extraction is compared to steady work extraction calculations based on various averaging techniques for characterizing the combustor exit pressure and temperature. It is found that averages associated with momentum flux (as opposed to entropy or kinetic energy) provide the best match. This result suggests that momentum-based averaging is the most appropriate figure-of-merit to use as a PGC performance metric. Using the mass-averaged work extraction methodology, it is also found that the design turbine pressure ratio for maximum work extraction is significantly higher than that for a turbine fed by a constant pressure combustor with similar inlet conditions and equivalence ratio. Limited results are presented whereby the constant volume cycle is replaced by output from a detonation-based PGC simulation. The results in terms of averaging techniques and design pressure ratio are similar.

\section{SUBJECT TERMS}

Gas turbine engine; Combustion

\begin{tabular}{|c|c|c|c|c|c|}
\hline \multicolumn{3}{|c|}{ 16. SECURITY CLASSIFICATION OF: } & \multirow{2}{*}{$\begin{array}{l}\text { 17. LIMITATION OF } \\
\text { ABSTRACT } \\
\text { UU }\end{array}$} & \multirow{2}{*}{$\begin{array}{l}\text { 18. NUMBER } \\
\text { OF } \\
\text { PAGES } \\
20\end{array}$} & \multirow{2}{*}{$\begin{array}{l}\text { 19a. NAME OF RESPONSIBLE PERSON } \\
\text { STI Help Desk (email:help@sti.nasa.gov) } \\
\text { 19b. TELEPHONE NUMBER (include area code) } \\
\text { 443-757-5802 }\end{array}$} \\
\hline $\begin{array}{l}\text { a. REPORT } \\
U\end{array}$ & $\begin{array}{l}\text { b. ABSTRACT } \\
\mathrm{U}\end{array}$ & $\begin{array}{l}\text { c. THIS } \\
\text { PAGE } \\
\text { U }\end{array}$ & & & \\
\hline
\end{tabular}



